УДК 621.3.066.6

АНАЛИЗ МАТЕРИАЛОВ ДЛЯ ЭЛЕКТРИЧЕСКИХ КОНТАКТОВ
ЭЛЕКТРООБОРУДОВАНИЯ ЖЕЛЕЗНОДОРОЖНОГО ТРАНСПОРТА

Инж. В.С. Морозов

АНАЛІЗ МАТЕРІАЛІВ ДЛЯ ЕЛЕКТРИЧНИХ КОНТАКТІВ ЕЛЕКТРИЧНОГО
УСТАТКУВАННЯ ЗАЛІЗНИЧНОГО ТРАНСПОРТУ

Інж. В.С. Морозов

\title{
ANALYSIS OF MATERIALS FOR ELECTRICAL CONTACTS OF RAILWAY TRANSPORT ELECTRICAL FACILITIES
}

Postgraduate V. Morozov

В статье проанализированы существующие материаль используемые, для электрических контактов на подвижном составе железнодорожного транспорта. Выяснено, что применяемые контактные материаль не отвечают требованиям современного машиностроения из-за своей высокой себестоимости, преждевременного изнашивания рабочей части, недостаточной дугостойкости, значительного удельного электрического сопротивления. Предложен новый материал на основе меди для электрических контактов, отвечающий требуемым характеристикам.

Ключевые слова: электрические контакты, технико-экономические показатели, дугостойкие композиционные материаль.

У статті проаналізовано існуючі матеріали, використовувані для електричних контактів на рухомому складі залізничного транспорту. 3'ясовано, що застосовувані контактні матеріали не відповідають вимогам сучасного машинобудування через свою високу собівартість, передчасне зношування робочої частини, недостатню дугостійкість, значний питомий електричний опір. Запропоновано новий матеріал на основі міді для електричних контактів, щя відповідає необхідним характеристикам.

Ключові слова: електричні контакти, техніко-економічні показники, дугостійкі композиційні матеріали.

The article analyzes the existing materials used for electrical contacts on railway rolling stock. It has been established that the presently used materials such as copper, silver, and composite materials based on them do not provide a predetermined service life of contacts and their operation reliability in operation, have a greater cost of repairs, do not possess the necessary resistance to the action of an electric arc, which occurs between contacts, working with arcing, have significant resistivity, do not provide a secure fit.

In this regard, the development of material for electrical contacts satisfying the technical and economic criteria of modern engineering is an important task. In such a situation, is effective to use a new material based on copper, containing titanium boride, graphite, zirconium oxide and titanium oxide. This composite has a high electrical discharge resistance, and low resistivity, long service life, eliminates the need for expensive components and can be used in high-current electrical circuits.

Keywords: electric contacts, technical and economic performance, arc-resistant composite materials.

Постановка проблемы. На современном этапе развития железнодорожного транспорта острой становится проблема повышения надёжности, безопасности и безотказности работы его электротехнического оборудования. Параметры, определяющие качество работы такого оборудования, зависят от многих факторов, таких как: качество и точность изготовления деталей оборудования, их сборки, материалов, из которых они изготовлены, правильное выведение оборудования на рабочие режимы и т. д. Большое количество машин приводится в действие электрическим током, поэтому в них имеется большее 
количество электрических контактов, работающих на замыкание и размыкание электрических цепей, и коммутирующих устройств, представляющих собой надёжное соединение двух проводников, позволяющее проводить электрический ток. Проблемы при эксплуатации электрических контактов связаны с применением дорогостоящих материалов, преждевременным изнашиванием рабочей части, отпаиванием электрических контактов от держателей, разрушением отдельных частей конструкций и др.

Поэтому разработка материала для электрических контактов, который обеспечивал бы безотказность работы электрического оборудования, снижение себестоимости ремонтных работ такого оборудования, повышение срока службы контактов и предотвращение отрыва электрических контактов от держателей являются актуальными задачами $[1,2]$.

Анализ последних исследований и публикаций. Большой вклад в изучение конструктивных особенностей, свойств материалов, технологию изготовления электрических контактов, а также исследования эрозионных процессов и характера токовой нагрузки внесли теоретические и экспериментальные работы таких ученых, как: В.Я. Берент, В.В. Измайлов, Ю.М. Королев, В.Н. Федоров, В.Я. Алехин, 3.В. Игнатьева, Н.В. Гуревич, Л.П. Строка, Л.С. Шмелев и др.

$$
\text { Надежная работа контактов, }
$$
осуществляющих размыкание и замыкание электрических цепей, определяется, прежде всего, элементами, обеспечивающими беспрепятственное прохождение тока. Специфика работы таких контактов обусловлена действием многочисленных факторов, зависящих от конструкции и материалов контактов, условий эксплуатации и воздействий внешней среды. Влияние перечисленного таково, что несмотря на правильно разработанную конструкцию и подобранный материал, контакты не могут при определенных внешних условиях обеспечивать надежную передачу электроэнергии. Таким образом, важной является задача по исследованию всех факторов, влияющих на работу электрических контактов, учет этих факторов в процессе поиска конструкторских решений, оказывающих влияние на работоспособность контактов, при подборе и разработке материалов для контактов, определении оптимальных условий эксплуатации каждой пары контактов.

Работа электрических контактов сопряжена со сложными физико-химическими процессами, протекающими на их поверхности. В эксплуатации на них образуются соединения, которые могут значительно повлиять на первоначальные свойства материала. В связи с этим важным является также изучение процессов на поверхностях контактов и межконтактном промежутке, что позволит оптимизировать требования к материалам контактов, условиям их работы и в конечном итоге повысить надежность коммутации тока [2-4].

Постановка задачи. Целью статьи является анализ существующих материалов, используемых для электрических контактов, и обоснование необходимости разработки нового материала, технико-экономические показатели которого удовлетворяют требованиям современного машиностроения.

Основной материал исследования. В соответствии с природой контакта, кинематикой движения, характером токовой нагрузки, конструктивными особенностями электрические контакты подразделяют на несколько типов. По геометрической форме контактных поверхностей контакты могут быть точечными, линейными, плоскостными, по токовой нагрузке - сильноточными и слаботочными, по кинематике неподвижными, разрывными, катящимися и скользящими. В зависимости от технологии выполнения неподвижные контакты могут быть паяными, сварными, клеевыми или зажимными с механическим соединением.

В качестве основных материалов для электрических контактов применяются: медь, серебро и композиционные материалы на их основе. В большинстве своем материалы, используемые для контактов, часто представляют собой смесь двух или более компонентов; многие из них получают методами порошковой металлургии.

Нашли применение цельнометаллические контакты (медь, платина, палладий, серебро, золото, а также вольфрам и молибден) и композиционные материалы, изготовленные методами порошковой металлургии (прессование заготовок из смеси металлических порошков и спекание их в высокотемпературных печах в вакууме или защитной атмосфере). Применяются также 
биметаллические контакты, состоящие из рабочего слоя - основного контактного материала, и нерабочего слоя - основания из меди, никеля, железа и др. [3,4].

В электрооборудовании подвижного состава железных дорог Украины широко распространены материалы на основе меди с добавлением вольфрама, серебра и сплавы на его основе. Один из таких материалов состоит из $90 \%$ вольфрама и $10 \%$ меди. Этот материал считается первым порошковым материалом и предназначен для работы электрических контактов при высоких температурах и высоких напряжениях.

Сплавы для контактов, такие как серебро - медь, серебро - кадмий и др., имеют по сравнению с металлами повышенную прочность и твёрдость, поверхность их не тускнеет, но их электро- и теплопроводность значительно ниже соответствующих чистых металлов. Для получения требуемых характеристик контактов в сильноточных цепях разрабатываются композиционные материалы, которые сочетают высокую электро- и теплопроводность с высокими температурами плавления и кипения, обладающие высокой смачиваемостью, низкой изнашиваемостью при работе и т. д. [5]. Материалы, которые используются для контактных элементов, способные прерывать ток большой величины, противостоять действию сильноточной электрической дуги, механическому воздействию, должны содержать в себе $40 \%$ или более тугоплавкого металла в сочетании с серебром или медью.

Для электрических контактов, работающих в условиях возникновения умеренной электрической дуги, возникающей при токах 50-150 A, в машиностроении применяется материал, состоящий из 85 \% Ag и около $15 \%$ $\mathrm{CdO}$. На железнодорожном транспорте данный материал широко применяется в контактах тяговых подвижных составов.

Зачастую, при выходе из строя электрических контактов такого типа, возникает проблема, связанная с их ремонтом. Это обусловлено тем, что замену или восстановление электрических контактов с использованием серебросодержащих материалов производят только на ремонтных заводах, а в условиях депо данный вид работы проводить не разрешено, также при восстановлении электрических контакторов возникает проблема приобретения серебросодержащего материала из-за его высокой стоимости.

Широко используются контакты на основе вольфрама, они изготавливаются методом порошковой металлургии с применением пропитки пористых заготовок вольфрамоникелевого сплава серебром или медью и предназначены для замыкания и размыкания электрических цепей в аппаратах управления приёмниками электрической энергии и её распределения [6].

Большинство контактов работают при высоких значениях напряжения, силы тока, давлениях и т. д. При работе в таких режимах между контактами велика вероятность появления электрической дуги, что увеличивает износ поверхности контактов и может привести к преждевременному выходу их из строя, а в последствии и к скорому выходу из строя всего оборудования в целом, на котором они установлены. Поэтому особое внимание уделяется дугостойким материалам. Они применяются в силовых контактах, которые работают с дугогашением, например, в контакте главного контроллера электровоза и в дугогасительных контактах, таких как быстродействующий выключатель постоянного тока. Основная функция силовых контактов коммутирование электрического тока при замыкании. Главная причина выхода из строя выгорание материалов контактов в дуге при размыкании. Функция дугогасительных контактов - гашение электрической дуги. Основные требования, предъявляемые к дугогасительным контактам, - это высокая дугостойкость и низкое удельное электрическое сопротивление.

На практике часто возникает вопрос об использовании материалов системы $\mathrm{Cu}-\mathrm{C}$, т. к. медь в этом случае является токопроводящим компонентом, а графит хорошо сопротивляется дуговому воздействию. При изготовлении таких материалов необходимо, чтобы графит смачивался медью для более надежной работы.

Проблема изготовления таких контактов заключается в том, что графит не взаимодействует с медью. Поэтому перспектива разработки материала для электрических контактов, работающих с дугогашением на основе системы, содержащей и углерод и медь, заключается в том, что медь должна надежно смачивать графит. Данная 
проблема решается в сплаве материала на основе меди, который содержит борид титана, графит, диоксид циркония и оксид титана. Данный композиционный материал обладает высокой электроэрозионной стойкостью, низким удельным и контактным сопротивлением, значительным сроком службы и позволяет отказаться от использования дорогих компонентов. Он может быть использован для сильноточных контактов в современном электрооборудовании [7-9].

Выводы. В связи с повышениями требований к электрическому оборудованию, связанных с повышением мощности и скорости тягового подвижного состава железных дорог, ужесточаются и требования, предъявляемые к их деталям, в том числе и к электрическим контактам. Остро стоит проблема, связанная с тем, что используемые на данный момент материалы, такие как медь, серебро и композиционные материалы на их основе, не обеспечивают заданный срок службы контактов и безотказность их работы в эксплуатации, имеют большую себестоимость ремонтных работ, не обладают необходимым сопротивлением действию электрической дуги, которая возникает между контактами, работающими с дугогашением, не обеспечивают предотвращения отрыва контактов от держателей. В этой связи, разработка материала для электрических контактов, удовлетворяющего техникоэкономическим критериям современного машиностроения, является важной задачей. В такой ситуации эффективным является применение нового материала на основе меди, содержащего борид титана, графит, диоксид циркония и оксид титана. Данный композит обладает высокой электроэрозионной стойкостью, низким удельным и контактным сопротивлением, значительным сроком службы, позволяет отказаться от использования дорогих компонентов и может использоваться в сильноточных электрических цепях.

\section{Список использованных источников}

1. Хольм, Р. Электрические контакты [Текст] / Р. Хольм. - М.: Изд-во Иностранной литературы, 1961. - 464 с.

2. Берент, В.Я. Материалы и свойства электрических контактов в устройствах железнодорожного транспорта [Текст] / В.Я. Берент. - М.: Интекст, 2005. - 408 с.

3. Бойченко, В.И. Контактные соединения токоведущих шин [Текст] / В.И. Бойченко, Н.Н. Дзекцер. - Л.: Энергия, 1978. - 1143 с.

4. Березин, В.Б. Справочник электротехнических материалов [Текст] / Н.С. Прохоров, Г.А. Рыков, А.М. Хайкин. - 3-е изд. - М.: Энергоатомиздат, 1983. - 399 с.

5. Нотон, Б. Применение композиционных материалов в технике [Текст] / Б. Нотон. - М.: Машиностроение, 1978. - 508 с.

6. Нотыч, А.А. Влияние легирования на свойства вольфрам-медных электрических контактов / А. А. Нотыч, В. Ф. Кроликов, А. А. Жилин // Перспективные материалы. - 1999. - №4. - С. 80-82.

7. Харитонов, Е.О Разработка материалов для силовых разрывных и дугостойких электрических контактов с повышенными эксплуатационными характеристиками, используемых на железнодорожном транспорте [Текст]: автореф. дис. ... канд. техн. наук: 05.02 .01 / Е.О. Харитонов; [Федеральное государственное унитарное предприятие "Всероссийский научно-исследовательский ин-т железнодорожного транспорта"]. - М., 2007. - 20 с.

8. Брон, О.Б. Проблемы электрических контактов в сильноточных аппаратах / О.Б. Брон // В сб.: Электрические контакты. - М.: Наука, 1973. - С. 7-15.

9. Харитонов, Е.О. Разработка дугостойких материалов для электрических контактов / Е.О. Харитонов // Сб. статей ученых и аспирантов "Развитие железнодорожного транспорта в условиях реформирования". - М.: Интекст, 2006. - С. 220-225.

Рецензент д-р техн. наук, професор Л.А. Тимофеєва

Морозов Володимир Сергійович, здобувач кафедри матеріалів та технологій виготовлення виробів транспортного призначення Української державної академії залізничного транспорту. Тел.: (057) 730-10-49. E-mail: a.domin@mail.ru.

Morozov Vladimir, postgraduate department of materials and manufacturing technology products transport purposes Ukrainian State Academy of Railway Transport. Tel.: (057) 730-10-49. E-mail: a.domin@ mail.ru. 